\title{
Application of Chinese traditional costume pattern in modern fashion design
}

\author{
HaiJun Zhang ${ }^{1, \text { a }}$ \\ ${ }^{1}$ Jiangxi Institute of Fashion Technology, Jiangxi, Nanchang, 330201 \\ hunter2011@foxmail.com
}

Keywords: Traditional; Clothing design; Clothing design; application

\begin{abstract}
Increasing with the economic globalization, China has become an important participant in the process of the globalization. China has a long history and culture, its art and culture also gradually affects the fashion design field, in the clothing design, several designers will be Chinese traditional clothing design and application of fashionable element combination, design the costumes were liked by people, occupy a certain clothing sales. This article first expounds the value of Chinese traditional costume pattern, and introduces its developing process, and then focuses on the meaning of the Chinese traditional costume pattern in modern fashion design and application.
\end{abstract}

\section{The introduction}

Throughout the Chinese clothing market has basic tend to westernization, fewer and fewer clothes with Chinese characteristics. How we will be traditional Chinese elements into fashion design, let people can buy clothes with Chinese characteristics and do not break vogue point, this also gives contemporary designer provides a point, we can't just expect from the west to their design, and fashion clothes should be designed with Chinese characteristics, and can get people's attention and recognition. Chinese traditional clothing design is the treasure of thousands of years precipitation under, its design is exquisite, to apply traditional costume pattern in modern fashion design is worth further exploration and research.

\section{The value embodiment of traditional costume design}

The concept of traditional costume design. Chinese traditional costume pattern which handed down from generations along with unique national art style design. He can be divided into the original social pattern, classical, folk and folk patterns, and patterns of ethnic minorities. These designs not only on the way of expression is varied, and can understand from these design decorative pattern on the local customs.

Pattern has been preserved from the primitive society of primitive society, mainly is the carving, painting and so on is used to describe the characters, animals, plants, water, fire, weaving lines, geometric lines and primitive religion, line is straightforward. Classic design is refers to the traditional pottery, stone tools, classic design has been passed down from ancient and has a pattern of a paradigm. He mainly comes from each at each generation in the gold and silver lacquer, grottoes, brocade, etc. And folk and folk pattern is created in the masses of the people and with the local folk style and characteristics of circulating pattern, these designs are reactions of the people's livelihood of the people, such as paper cutting, embroidery patterns. Ethnic pattern is refers to the ethnic minorities in the long-term production and life create and spread the design with the national characteristics. These patterns have unique different region amorous feelings, like kazak carpet pattern, buyi wax printing. Also includes the broad Chinese traditional pattern like traditional drama, traditional architecture and classical garden, the visual form of visibility. These varied design decorative pattern creates the rich material for modern clothing designers.

China's ancient costume design, like neutrals, peony, wufu holds shou, kirin, chapter 12 decorative design in a utensil, etc. Longfeng pattern is the product of the Chinese feudal culture, is a symbol of wealth, imperial power, but in the folk were clever adaptation, such as application spends 
on fabric pattern. Along with the development of economy, the progress of the society, now the designers of the Chinese traditional pattern is applied to clothing, improvement on the technique of processing the application of the more common methods, such as embroidery, applique embroidery, printing and dyeing, etc. Through this a series of clothing and accessories on the modernization of processing, make the patterns more modern fashion. With the 2008 Beijing Olympic Games successfully held, more and more Chinese elements design is clothing brand used in design, its extremely national appeal of the Oriental color matching with the details of the western modern clothing processing, give the world a different visual perception. Especially in recent years, the international Chinese wind blowing strongly, as the 2013 Paris fashion week Tsumori Chisato China fan handbag, John galliano ink and digital printing clothing, valentino gown of blue and white porcelain and other traditional Chinese design, was adorned in different parts of the garment, which shows the charm of Chinese culture, will also be the modern aesthetic feeling.

The value of Chinese traditional costume pattern. Chinese traditional costume pattern used in modern fashion design is more and more shows a unique charm, to bring endless inspiration in the world of fashion design, fashion designers often at home and abroad to join Chinese costume elements in the design work, to design brings new life and vigor.

Artistic value. Traditional dress of China often use the craft technique, such as embroidery, Mosaic, piping in the design and use the elements, such as painting of flowers and birds on the on the fabric is according to the hierarchy of the different fabrics such as cotton, hemp, silk. Chinese traditional clothing often use line rhyme verve, so often in the process of cutting scale cutting, in the form of a clothes bo sleeve. This model reflects the ancient concept of "nature round place". The development of the eastern and western cultures have different, but with the development of the modern world economic integration, the world culture in imperceptible in mutual penetration, are intertwined, and gradually formed a new art form. Chinese traditional costume pattern has a large number of applications in the field of different design, to the modern civilization bring different visual feeling.

Humanistic value. Costume designer according to the different regional culture and aesthetic psychology to design clothing, such as the differences, the differences between the east and west, north and the south and the differences of different national costume design in the same area. In Chinese traditional culture, the moral of many Chinese traditional pattern has a blessing, for example: the jade has the meaning of good fortune as one wishes. For clothing designers, if add the traditional Chinese design elements in the Chinese market, for Chinese consumers are familiar with and can accept, which means will bring consumers to buy the orientation.

\section{The meaning of Chinese traditional costume pattern in modern fashion design}

China has a long-standing culture, give her a steady stream of modern garment design inspiration, but also affects the way of thinking and forms of clothing designers. "National is the world" is the best evidence influence on Chinese culture to the world. Chinese traditional clothing design is how to better application in the clothing design, first of all should be based on Chinese traditional culture, to understand Chinese culture contains profound meaning, many nationalities in China, long dress culture, which is the precious wealth, designers have to use the fine Chinese traditional costume pattern based on the process technique of modern popular clothing design, can design with Chinese style, which is Chinese traditional costume pattern can be incorporated into one of the methods of modern fashion.

\section{Application of Chinese traditional costume pattern in modern fashion design}

In the clothing design in the design of the application . Throughout the Chinese traditional clothing, in the collar, sleeve pattern design is a bright spot, collar, sleeves, also is one of the focus of the fashion design, the collar can foil a person the aesthetic feeling of the head. In recent years, the design of collar, is loved by people of collar is a classic Chinese elements, one of the most famous is the "Chinese tunic suit", during the period of the republic of China in modern times, after 
the change of some of the details, the collar width is narrower, become more fit, gradually formed a "Chinese collar" now. This design is especially suitable for the Chinese, to be able to reflect the wearer's overall qualities. Sleeve in the Chinese traditional clothing, according to the size of the cuff, narrow mouth can be divided into the jar, sleeve cuff. For modern men's wear, sleeve, sleeve circumference progressively smaller sleeve type gradually become the mainstream, coupled with some traditional adornment gimmick, such as embroidery, then Chinese traditional costume pattern is blended in among them, make the wearer look more spirit, at the same time can also reflects the unique flavor.

The application of combined with modern craft technique. China pattern after one thousand years of evolution gradually formed its own style, in the modern fashion design, pattern in the way of application in China has more choices, designers like with traditional pattern inherent in the form and design combined with printing and dyeing process. For example the T-shirt design is mainly use this technique, combining with the current widely used rubber paste printing, make design directly with clothing. But such design methods lack of originality, frequent use is easy to make consumers produce aesthetic fatigue. Therefore, modern designers have adopts restructuring, segmentation, topical application method, make the traditional pattern of more modern. For fashion design, apparel design the part of the application is also very important. The application of modern clothing design more diversified, collar point, collar, sleeves, trousers, pockets, will be used in areas such as the waistband, and even many clothing used in printed form. In conclusion, the modern costume design in the design, like subversion, don't blindly copycat.

The application of the fabric. In the history of Chinese traditional costume pattern in the textile fabrics application has for a long time. In cotton, hemp, silk and wool fiber, the big four of the most famous is the silk, China is the world's largest cocoon silk production, its production accounted for more than $71 \%$ of world output. Silk, with its unique luster, good moisture absorption, widely used in modern clothing, suitable for shirt, coat, dress. Along with the continuous renewal of modern textile technology, from the original natural textile to now and the combination of the new type of chemical fiber fabrics, silk fabrics in the constant change of the preference of the people at the same time. In the modern fashion design, silk fabrics won't be a single use, often combined with some traditional moral and full of beautiful designs, make clothing more can attract the attention of consumers.

In the application of clothing accessories. Accessories are elements of a brand in the design of clothing style. In modern fashion design, how to embody the Chinese elements, the designers played their ideas. In addition to the Chinese dish, cloth, side open fork, piping process these traditional clothing accessories, the designer will according to the characteristics of their own clothing and shoes, leather bags, full of Chinese characteristics of necklace. Although these elements cannot tell from which dynasty, but it is an inalienable part of Chinese costume culture. Is good at Chinese, for example, Chinese designer Zeng Fengfei deserve to act the role of the application in the modern clothing. Waist sealing, welt are the characteristics of the clothing design, and the element of these accessories will be combined with Chinese traditional costume pattern.

\section{Conclusion}

Chinese traditional costume pattern has a pivotal position in the clothing design, it contains the feelings five thousand years of Chinese history and folk complex, to the present field of fashion design provides a rich resource and wealth. Designers need to constantly to dig deeper into the connotation of Chinese traditional culture, absorb the traditional Chinese art creation technique, combined with modern garment design methods and techniques, to create fashionable clothing pattern with Chinese characteristics.

\section{Reference}

[1] D.J. Qi, X.Y Liu.. Costume design application in modern fashion design, Art and design (theory), 5 (2012) 45-47. 
[2] X.L. Qi. The application of Chinese traditional design element in modern clothing design, Design, 10 (2014) 78-79.

[3] J. Miao. The application of traditional costume elements in modern fashion design analysis, Journal of changsha railway institute (social science edition), 12 (2013) 13-15.

[4] G.L. Ren. Chinese traditional pattern combined with modern western costume design concept in the application of the clothing accessories, Sichuan normal university, 5 (2013).

[5] Q. Li. The application of Chinese traditional pattern in modern fashion design, Suzhou university, 10 (2008). 